will be seen that the spirit of this recommendation is fully realized in Manitoba's new Act.

The migration of the Snowy Owl in the winter into the plains of Saskatchewan coincides almost exactly with the period for which protection is not afforded it. At the Annual Meeting of the Saskatchewan Natural History Society in October, 1963, a resolution was passed asking the De- partment of Natural Resources to give protection to the Snowy Owl. Although we are informed by the Wildlife Branch (letter of January 15, $1964)$ that legislation is not being prepared this year to amend the section of the Game Act pertaining to the protecticn of hawks and owls, the progress made in Manitoba in acquiring further protection enccurages us to continue to work for similar revisions in the Saskatchewan Act.

\title{
Hope for Water Birds Subjected to Detergents?
}

\section{by J. R. Jowsey, Regina.}

A clear example of injury and death of water birds brought about by a concentration of waste detergents in sewage lagcons has been described by Robert W. Nero (Blue Jay, Sept., 1963, p. 91). Such undesirable conditions may be decreased soon for chemical engineers seem to be advancing fairly rapidly in the solution of the detergent foam problem in sewage (Chemical and Engineering News, March 18, 1963, p.102, and Nov. 4, 1963, p.138). However, this may or may not completely solve the problem of wetting of water birds due to "de-greasing" by detergents. Perscns interested in the welfare of our waterfowl might therefore take ncte of some of the additional features of the problem.

More rapid destruction of waste detergents by microorganisms (resulting in less foam) may be brought about as the result of the use in detergents of new raw materials which are less resistant to biodegradation (Chem. and Eng. News, Nov. 4, 1963, p. 138). If such degradation requires an appreciable time (e.g., six hours), however, birds may still be exposed to considerable hazard. The foam problem is already causing a swing away from the alkylbenzene sulfonate-based detergents because of the high resistance to the alkylbenzene sulfonates to biodegradation, and this will no doubt bring about scme reductions in the hazards to waterfowl.

Also, if the rate of reduction of foam hazard is more rapid than reduction in "de-greasing" action of detergents, then the problem of foam- ing may be resolved without any reasonable measure of protection of waterfowl being effected. The "degreasing" action on waterfowl, and the cleansing action of a soap or a detergent, may be brought about by a substance with a molecular structure which provides a satisfactory combination of radicals with an attraction for water and those with an attraction for fats and oils. It is possible, therefore, that development of a "ncn-foaming" detergent might bring about only negligible reduction in hazard to waterfowl.

In Saskatchewan the rapid increase in the number of tcwns with sewer and water services, and the many advantages of the sewage lagoon, will further increase the hazards for waterfowl if control of the "degreasing" by waste detergents is not maintained. Additional cost due to introduction of a chemical or rapid biological method of degradation in order to ensure relatively complete and rapid destruction of detergent residues may be necessary if our waterfowl are to be protected adequately from hazardous concentrations of surface-active agents in sewage lagoons.

Ed. Note: Dr. James R. Jowsey, a member of $\operatorname{rir}$ Society, is presently Science Teacher at Thom Collegiate in Regina. He has a special interest in chemistry and biology and has previouly carried out research on various problems in the nutrition of domestic animals, including birds.

R. W. Nero's article on waste detergents (Blue Jay 21:91) which is referred to in this article has been used as an illustrated feature: "Detergents - Deadly Hazard to Water Birds" in the last issue of Audubon (66:26-27), official publication of the National Audubon Society. 